\title{
Surface pressure disturbance in the Ebro Valley (Spain) produced by the Pyrenees mountains during PYREX
}

\author{
By J. DÍAZ DE ARGANDOÑA ${ }^{1 *}$, A. EZCURRA ${ }^{2}$ and B. BÉNECH ${ }^{3}$ \\ ${ }^{1}$ Departamento de Física Aplicada I, Universidad del País Vasco-Euskal Herriko Unibertsitatea, \\ Vitoria-Gasteiz, Spain \\ ${ }^{2}$ Departamento de Física Aplicada II, Universidad del País Vasco-Euskal Herriko Unibertsitatea, \\ Vitoria-Gasteiz, Spain \\ ${ }^{3}$ Centre de Recherches Atmosphèriques, Laboratoire d'Aérologie UMR UPS/CNRS 5560,
}

Lannemezan, France

\begin{abstract}
In this paper, the pressure anomaly created by the Pyrenees during the Pyrenees Experiment (PYREX) in the Ebro Valley is studied and analysed. In the first part, pressure disturbance is obtained during some selected cases of PYREX by subtracting the synoptic component from the pressure registered by microbarographs and regular meteorological stations located in the area. As expected from a linear model, a low pressure is found for northerly synoptic winds and a high pressure for southerly synoptic winds. Data shows that the maximum pressure anomaly observed may reach values of the order of $7 \mathrm{hPa}$. Pressure-anomaly spatial patterns found inside the valley are classified by using principal component analysis (PCA). It is found that the first axes deduced from the PCA carried out represent $75 \%$ of the variance in pressure data, indicating that all the stations analysed observed pressure anomalies in a correlated manner. Pressure anomalies are then related to incident-air characteristics expressed as Froude and Rossby numbers. Significant correlation is generally found with these numbers in all cases, demonstrating the dynamic origin of the pressure anomaly computed.
\end{abstract}

KEYWORDS: Pressure anomaly Principal component analysis

\section{INTRODUCTION}

During recent decades the effect of complex topography, and especially mountain ranges, on atmospheric circulation has been studied extensively, both observationally and theoretically. Several factors explain this intense attention: in particular the necessity of developing increasingly exact parametrizations of topographic effects in mesoscale numerical models and the study of pollutant dispersion in complex terrain, among others. Large-scale experimental campaigns, such as the Alpine Experiment (ALPEX) in the Alps and the Pyrenees Experiment (PYREX) in the Pyrenees, have played an important role in the tuning and validation of numerical models and, no less importantly, in the application of simple theoretical models in real-world situations to explain phenomena such as flow splitting around the mountains or stagnation of the air. As a result of these studies, it is current knowledge that large mountain ranges such as the Alps, Andes, etc. significantly disturb regional airflow and pressure, producing local winds and pressure disturbances.

Surface pressure disturbances created dynamically by mountains are considered one of the most important dynamic effects produced by mountains on the atmosphere (Smith 1980). Compared with the wind disturbance, a pressure disturbance penetrates the boundary layer and can be easily detected at the surface. Dynamic effects on wind currents, such as blocking and deflection, can be considered to be effects of the surface pressure gradients rather than direct effects of the solid mountain slopes (Smith 1982).

Several theoretical frameworks can be considered when studying the influence of mountains on the atmosphere; for example, Drazin's theory (Drazin 1961), applied to cases in which a strongly stratified air mass is unable to ascend the mountain slope,

* Corresponding author: Departamento de Física Aplicada I, EUITI y T, Universidad del País Vasco, C/ Nieves Cano 12, 01006-Vitoria, Spain. e-mail: wupdigoj@vc.ehu.es 
and is then forced to circumvent the mountain. In the present paper we will focus on linear theory. This theory has been developed by several authors. Lyra (1943) and Queney (1947) among others, applied this theory to bi-dimensional obstacles, and Smith (1980) used this theoretical approach to study the steady flow over an isolated, three-dimensional obstacle.

Linear theory results in a very important simplification of the equations of motion, continuity and thermodynamics by neglecting all nonlinear terms. In this way, linear theory should be applied only when disturbances in the atmospheric variables are minimal enough to dispense with their products within the equations. Nevertheless, several research studies, such as Smith (1982, 1989), Stein (1992), Bougeault et al. (1991), Bénech et al. (1998) and Koffi et al. (1998) have shown that results obtained by using this simplification can even predict certain nonlinear flow characteristics-such as stagnation points-well out of its expected range of validity.

The linearized equations of motion, continuity and thermodynamics can be easily resolved by using the Fourier transformation. According to results found by Smith (1980) who followed this method of solution, the main disturbance to atmospheric circulation caused by mountains can be described as a symmetric dipole of pressure anomalies located around the mountain: the so-called orographic dipole, that is considered to be the cause of the diverted flux observed around the mountain. Smith (1980) also showed that the linear theory applied to an analytical, bell-shaped relief, predicts a pressure disturbance in proportion to the product $N U, U$ being the wind intensity of the air blowing against the mountain and $N$ the Brunt-Väisälä frequency (the freefrequency oscillation of a parcel of air moving adiabatically, vertical to the incoming air mass). This last parameter is closely related to the static stability of the air through the relationship:

$$
N=\sqrt{\frac{g}{\theta} \frac{\partial \theta}{\partial z}}
$$

where $\theta$ represents the potential temperature, and $g$ the gravitational acceleration.

Several qualitative observations of pressure disturbance around mountains of different scales have been carried out, for example by Aanensen (1965), Blanchard and Howard (1986), Reed (1980) and Smith (1982), but comparatively little effort has been made to effect quantitative measurements of the intensity and position of the disturbance. Among these measurements, the Olympic Experiment (OLYMPEX) must be cited (Mass and Ferber 1990). In that experiment a specially devised array of microbarographs was used to measure the pressure disturbance, and the results were compared with linear-theory predictions.

During October and November 1990, an experimental programme named PYREX (Pyrenees Experiment) was launched on both sides of the Pyrenees range, in order to obtain intensive measurements of the dynamic influence of this mountain range on the atmosphere (for more details of this programme, readers can refer to Bougeault et al. (1993)). The Pyrenees is a fairly simple mountain range, lying on the Spanish-French border. It is about $400 \mathrm{~km}$ long and, at the centre, about $80 \mathrm{~km}$ wide with a maximum height of about $3000 \mathrm{~m}$. To the south of the Pyrenees, the Iberian range (whose height does not exceed $2000 \mathrm{~m}$ ) delimits the Ebro Valley, an almost flat river valley with a triangular shape. In the central part of this valley, a well known north-westerly local wind called cierzo, blows with a constant direction along the axis of the valley when northerly synoptic wind flows against the Pyrenees. Figure 1 presents the topography of the study area. 


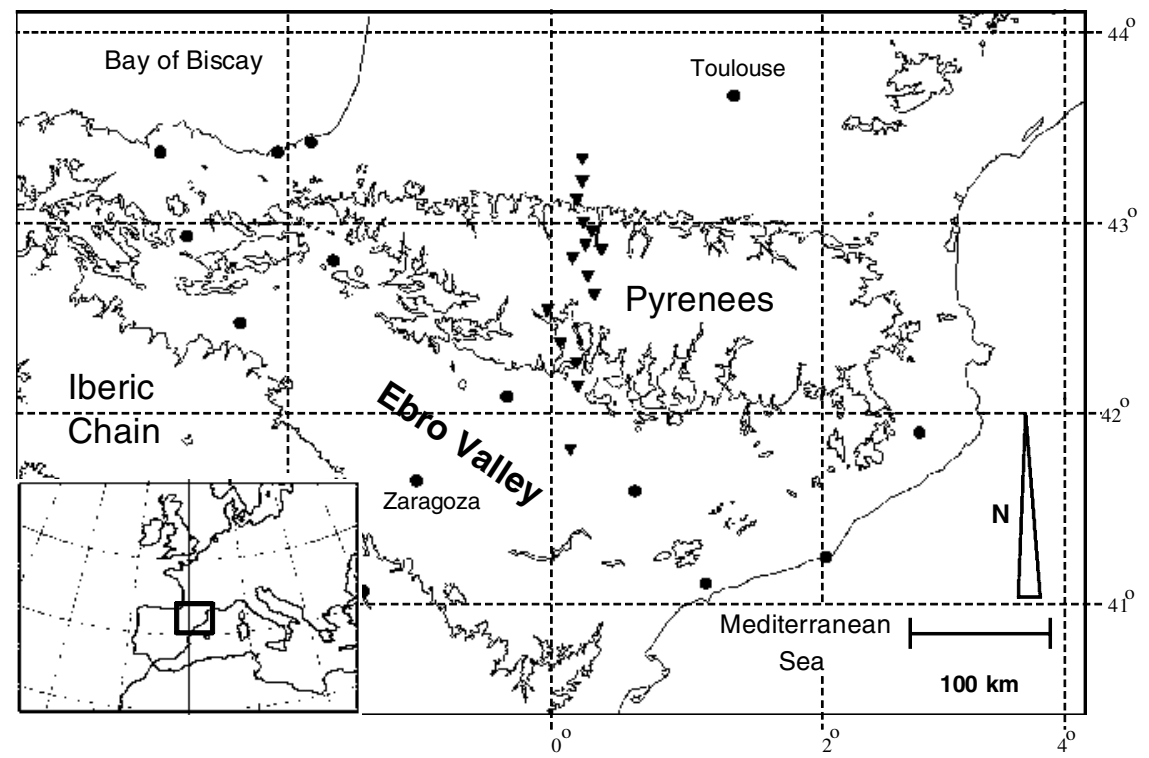

Figure 1. Topography and measurement stations of the study area. The solid dots represent regular stations and the solid triangles the microbarograph network for the drag measurement. The $800 \mathrm{~m}$ height level is shown.

Some dynamic effects, especially the blocking of the incident air and the development of local winds such as the tramontana and the above-mentioned cierzo for northerly flow, and the autan for southerly flow, can be attributed to the disturbances created by the Pyrenees in the atmospheric circulation, and it is thought that the southerly component of the pressure anomaly created by the Pyrenees plays an important role in the development of the latter wind (Vazquez 1992). The main objective of PYREX was to quantify the dynamical influence of the Pyrenees in the local atmospheric circulation, to improve the parametrization of this relief in numerical models, and to study some of the winds cited above. In view of this, one of the major parameters measured during PYREX was the pressure mountain drag (Bessemoulin et al. 1993). The drag is a magnitude related to the momentum transfer between the air mass and the mountain and, therefore, it measures the dynamic disturbance of the flux. During the PYREX campaign drag was obtained with a network of 14 microbarographs lying in a transect perpendicular to the axis of the mountain (see Fig. 1). The pressure drag per unit area can then be easily derived from the pressure measured across the mountain (Davies and Phillips 1985), by using the expression:

$$
d=\frac{1}{L} \int_{Z_{\text {bottom }}}^{Z_{\mathrm{top}}} \Delta p \mathrm{~d} z
$$

where $d$ represents the drag per unit area, $Z_{\text {top }}$ and $Z_{\text {bottom }}$ are, respectively, the altitude of the highest and the lowest stations, $\Delta p(z)$ the pressure difference across the mountain at height $z$ and $L$ the width of the instrumented section. This integral was evaluated by Bessemoulin et al. (1993) for PYREX by using a two-step procedure. First, a spline interpolation was computed from the altitudes of the stations, permitting the description of the topography height as a function of distance $x$. Second, a similar operation performed on $\log p$ providing the horizontal variation of $\log p$ along the $h(x)$ surface, allowed the computation of horizontal pressure differences and, therefore, the evaluation of the integral in Eq. (2). The pressure-drag values obtained took values from 8 to 
$-7 \mathrm{~Pa}$ (by convention it is positive when the pressure is higher on the northern side of the range). The mean of its absolute value is about $2.2 \mathrm{~Pa}$ during the two month period, indicating that the Pyrenees is a significant sink of momentum. The same author observed a close correlation between drag and the pressure dipole across the mountain.

The objective of this paper is to study the pressure disturbance in the Ebro Valley, at the southern edge of the Pyrenees during PYREX, and to relate this parameter to the characteristics of the incoming flow.

\section{PRESSURE-DATA TREATMENT}

All the available stations with a pressure sensor operating during PYREX were used to obtain the spatial distribution of pressure in the Ebro Valley. The data from the southern part of the high-precision microbarograph network used to measure the drag represent the core of the database, but automatic weather stations spread along the Ebro Valley were used as well. Figure 1 shows the locations inside the valley of the pressure measurement points used in this paper, as well as the full microbarograph network. As stated above, only the southern part of the microbarograph network was used for pressure measurements. Regarding the spatial distribution of the network used we note that the northern central part of the valley is quite well covered, but the sides and the southern area have scarcer coverage. Nevertheless, the expected dipole of pressure disturbance created by the Pyrenees when winds blow perpendicular to the axis of the mountain (the most interesting cases), must occur in the area covered by the microbarograph network.

In order to use the pressure data collected during the experimental campaign, some corrections had first to be made. In the first place a careful inspection was carried out in order to remove all the spurious data from the database. It was also necessary to reduce the pressure measured by each individual instrument to a common level in order to compare the different values observed by the network. With this aim the Laplace equation was used (Triplet and Roche 1977) to reduce the pressure data to sea level. In order to work out the mean temperature of each layer, the temperature gradient deduced from the available radiosoundings in Zaragoza (see Fig. 1) was used. The gradients found are in general quite close to $0.0065 \mathrm{~K} \mathrm{~m}^{-1}$, considered to be a mean value, and vary from $0.0042 \mathrm{~K} \mathrm{~m}^{-1}$ to $0.0072 \mathrm{~K} \mathrm{~m}^{-1}$.

The acquisition frequency of the sensors was quite different between the microbarograph network (about 10 minutes) and the regular meteorological stations (in some cases four observations per day), so a daily mean of the pressure was made in order to compare the pressure data.

In order to work out the pressure anomaly inside the valley, the synoptic pressure field had to be elucidated, the synoptic pressure being the pressure that should be observed in the valley were no dynamic influences of the mountains present. From this pressure field, the anomaly could be estimated by simply subtracting the synoptic field previously calculated from the pressure measured by every station. Different methods have been proposed in scientific literature to calculate this synoptic field. Bénech et al. (1998) for example, used the geostrophic wind to estimate the synoptic pressure gradient. Mass and Ferber (1990) made an interpolation of data from stations far enough from the mountain to be certain that little or no dynamic influence could be present in the undisturbed pressure field calculated. This second approach was used in our study. Due to the shape of the Pyrenees, interesting situations are those with an incident synoptic wind perpendicular to the main range axis, i.e. northerly or southerly flow conditions. In these cases, the synoptic pressure gradient is almost parallel to the mountain range, 

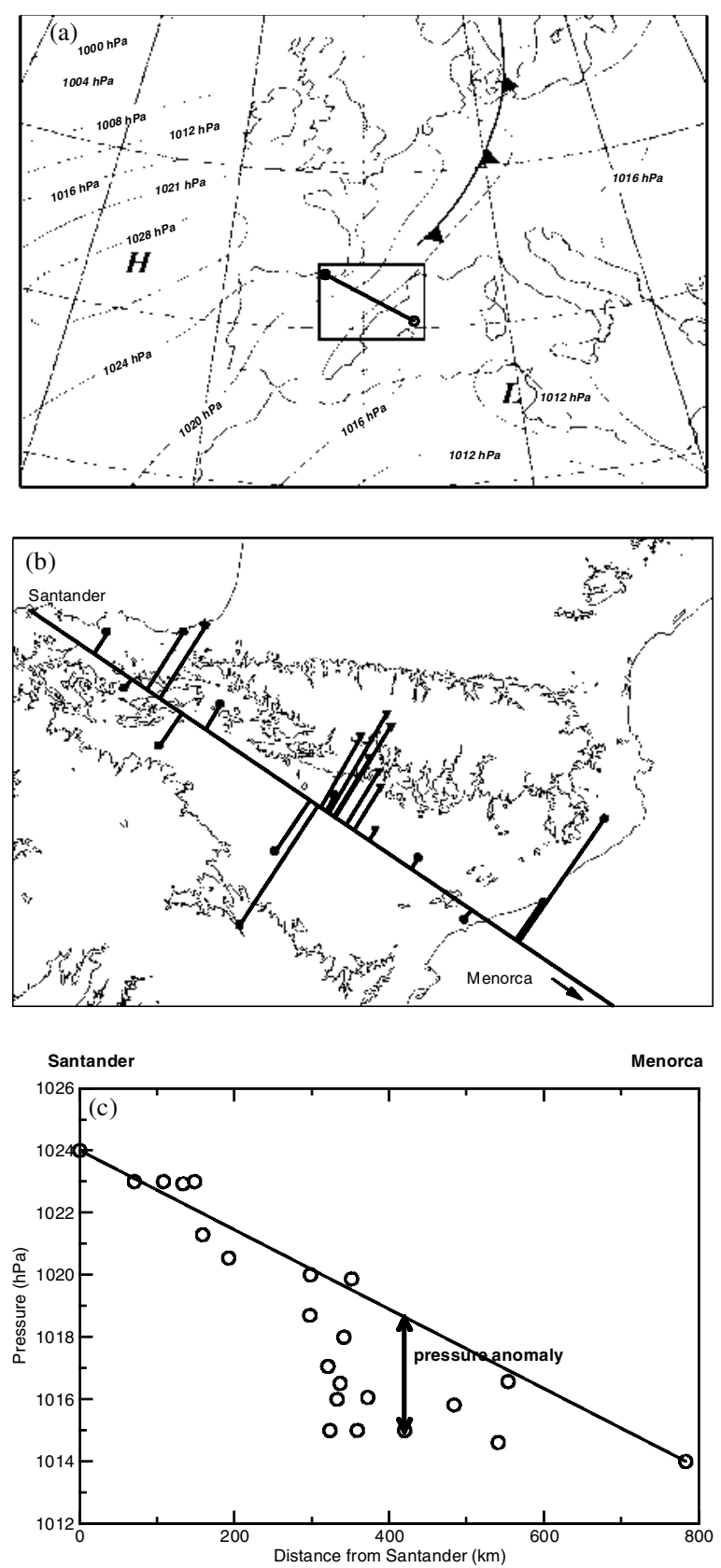

Figure 2. Process of determining the pressure anomaly in the 4 October case: (a) surface synoptic map, indicating the quasi-perpendicular to the Pyrenees isobars. (b) The stations used to estimate synoptic pressure were Santander and Menorca, at the extremes of the valley axis. (c) The pressure anomaly is obtained by subtracting the linearly interpolated synoptic pressure from the measured pressure. 
and little or no variation in synoptic pressure is to be expected along the north-south axis.

Therefore, a number of days from the PYREX database with synoptic characteristics close to the ones cited above were selected: 12 with northerly flow and 9 with southerly flow.

The synoptic pressure field was estimated by linear interpolation of the pressure measured at two stations far enough from the influence of the Pyrenees and located on the axis of the Ebro Valley: Santander on the coast of the Atlantic Ocean, and Menorca, one of the Balearic islands. A linear estimation shows that the pressures at these two points are not significantly influenced by the mountain anomaly. This result suggests that the assumption of no pressure perturbation in these stations is quite reasonable.

Figure 2 illustrates the process described above for the case of 4 October 1990 . The synoptic surface analysis map (Fig. 2(a)) shows a pressure gradient parallel to the valley. Figure 2(b) indicates the position of the stations and the straight line used to interpolate the pressure of the two extreme stations. The synoptic pressure at a given station is considered to be the one obtained by the interpolated pressure between the two extreme stations at the position of the station projected onto the line. As seen in Fig. 2(c), a low-pressure disturbance with a maximum of about $4.5 \mathrm{hPa}$ is found for this day, subtracting the synoptic pressure interpolated inside the Ebro Valley from the pressure data observed at every network station.

It is difficult to quantify the accuracy of the values of pressure anomaly obtained, but the results, as explained below, are consistent with expected theoretical predictions. For example, the anomaly pressure values from the different stations are highly correlated, as discussed in the next section, indicating that all the stations measure a common phenomenon. Moreover, we obtain a low-pressure anomaly in the Ebro Valley for northerly winds and a high-pressure anomaly for southerly winds.

\section{RESULTS OF PRESSURE ANOMALIES}

The extreme values of pressure disturbance found following the procedure explained above, are shown in Table 1 for the different days considered in our study. The mean pressure drag per unit area calculated for each day studied is also presented in this table. The results found are in good qualitative agreement with the results of linear theory: we obtain a low pressure for northerly winds and a high pressure for southerly winds. However, an anomalous case is observed on 11 November: on this date the value of the drag per unit area was close to zero $(0.1+0.7 \mathrm{~Pa})$. Therefore, the type of situation associated with this day (northerly or southerly flow) is not well defined.

We also note that the highest and lowest pressure anomalies found were of the order of $7 \mathrm{hPa}$. Finally, no information was obtained regarding the symmetry of the dipole, because only its southern component was treated in this paper. With respect to the magnitude of the dipole readers can refer, for example, to Bénech et al. (1998), Koffi et al. (1998) or Genovés and Jansá (1993).

The pressure anomaly observed by every instrument can be used to obtain spatial distributions within the Ebro Valley. Figure 3 shows three different patterns obtained when a krigging interpolation is used to that effect during northerly wind conditions. Figure 3(a) shows a quite typical situation found: a low-pressure area is centred near the Pyrenees at the midpoint only. Nevertheless, in Fig. 3(b) we present a case in which the low pressure previously shown is located much further south, and finally in Fig. 3(c) we present an example of one day when a more complex pattern was obtained. 
TABLE 1. EXTREME VALUES OF THE PRESSURE DISTURBANCE FOUND FOR SELECTED DAYS. THE MEAN AND STANDARD DEVIATION OF DRAG PER UNIT AREA ON EACH DAY IS ALSO SHOWN.

\begin{tabular}{cccc}
\hline Day & $\begin{array}{c}\text { Synoptic } \\
\text { wind direction }\end{array}$ & $\begin{array}{c}\text { Extreme } \\
(\mathrm{hPa})\end{array}$ & $\begin{array}{c}\text { Drag } \\
(\mathrm{Pa})\end{array}$ \\
\hline 04 October & North & -5.0 & $+4.4 \pm 1.4$ \\
05 October & North & -3.3 & $+3.6 \pm 0.9$ \\
08 October & North & -6.2 & $+6.3 \pm 1.0$ \\
09 October & North & -1.1 & $+2.7 \pm 0.7$ \\
12 October & South & +4.9 & $-2.6 \pm 0.6$ \\
14 October & South & +5.3 & $-2.3 \pm 1.1$ \\
15 October & South & +5.3 & $-4.1 \pm 1.4$ \\
16 October & South & +4.5 & $-3.0 \pm 0.6$ \\
18 October & South & +2.4 & $-1.5 \pm 0.3$ \\
21 October & South & +2.7 & $-1.5 \pm 0.6$ \\
22 October & South & +6.8 & $-3.3 \pm 0.7$ \\
04 November & North & -4.3 & $+2.2 \pm 0.3$ \\
07 November & South & +6.9 & $-3.1 \pm 0.8$ \\
08 November & South & +6.9 & $-4.0 \pm 0.8$ \\
11 November & North & +3.3 & $+0.1 \pm 0.7$ \\
15 November & North & -7.2 & $+5.0 \pm 1.0$ \\
16 November & North & -5.2 & $+5.6 \pm 1.4$ \\
17 November & North & -4.9 & $+3.1 \pm 0.6$ \\
18 November & North & -6.1 & $+3.6 \pm 0.4$ \\
28 November & North & -6.5 & $+2.1 \pm 0.4$ \\
29 November & North & -6.2 & $+2.6 \pm 0.4$ \\
\hline
\end{tabular}
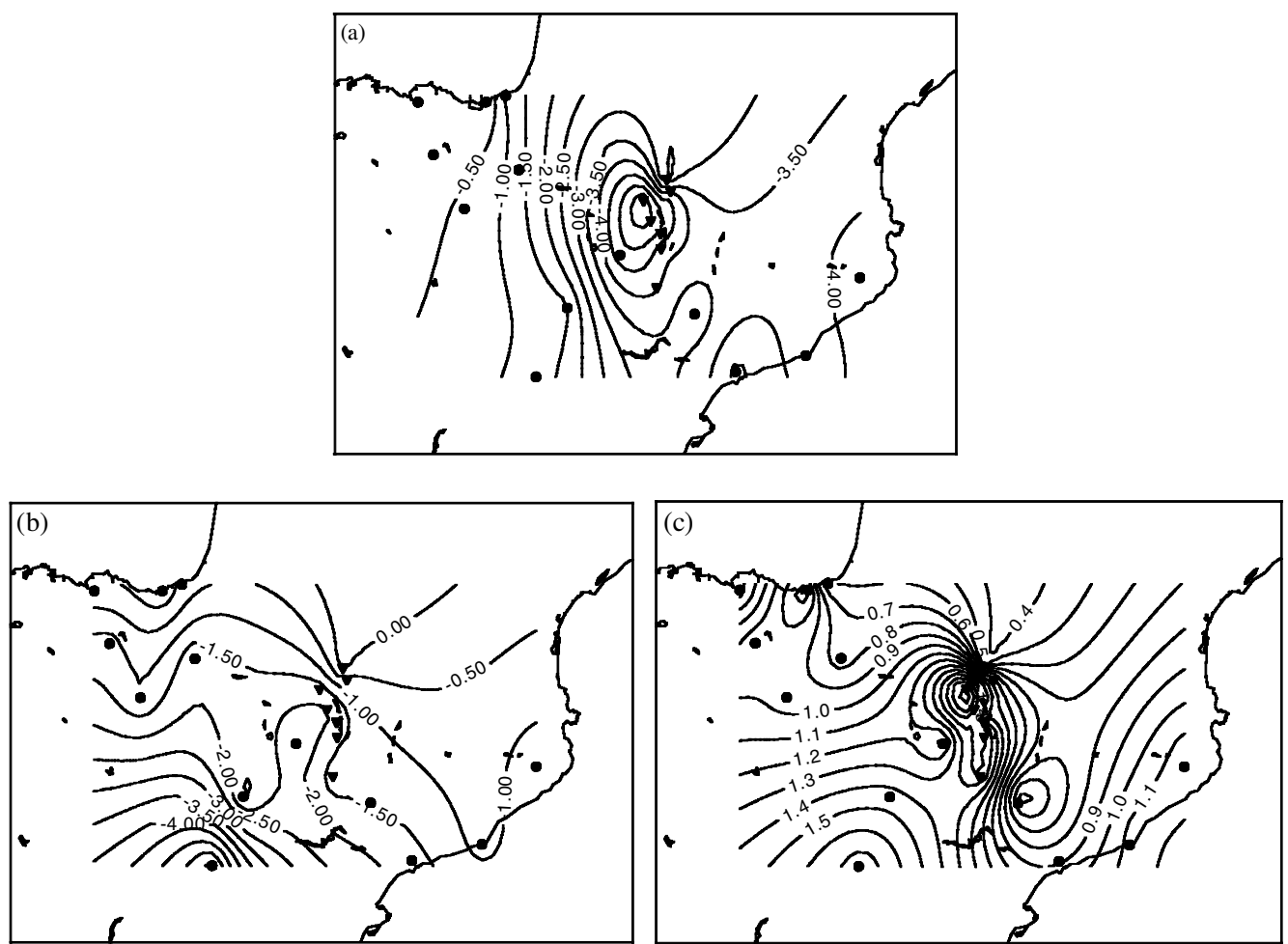

Figure 3. Some typical pressure disturbance patterns found (hPa). 

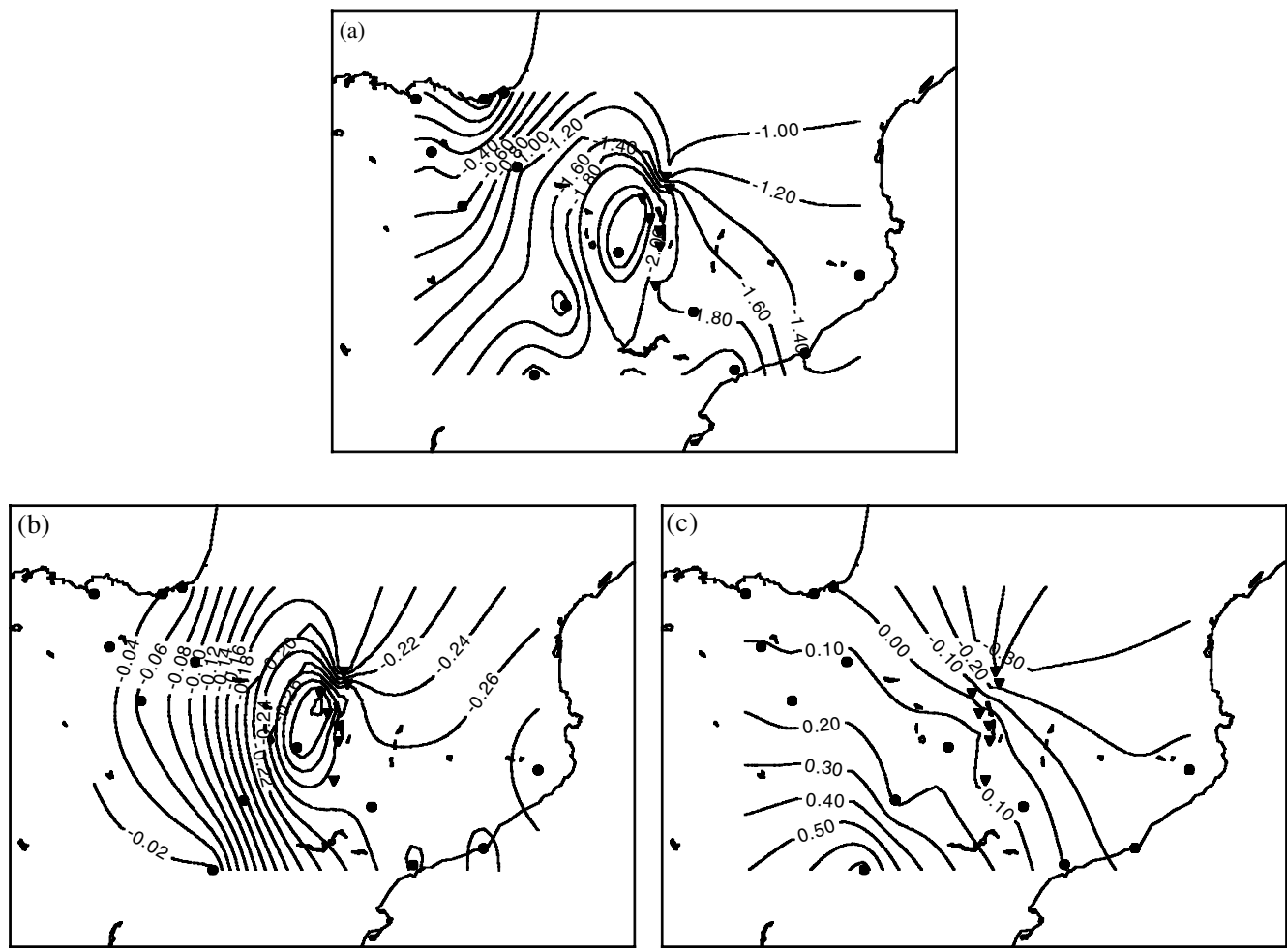

Figure 4. Isolines of mean value and first two principal axes for northerly wind situations. (a) Mean pressureanomaly isolines (hPa). (b) First principal axis isolines. (c) Second principal axis isolines.

In order to better understand the spatial distribution of pressure anomalies produced inside the valley, we performed a centred principal component analysis (PCA) on the data. Northerly flow and southerly flow situations were considered separately, because different mechanisms and physical processes are thought to occur, mainly due to the fact that a different topography is found on the north (quite flat) and south (very complex) faces of the Pyrenees.

Figure 4 shows the spatial distribution of the mean values of pressure anomalies observed by the network during the days treated in this paper, and the spatial distribution of the first two principal axes computed by PCA during northerly wind situations. Southerly situation means and axes are completely analogous (the mean is a highpressure perturbation in this case). We have to remark that the explained variance of the two principal axes interpolated inside the valley represents about $85 \%$ in both cases. We also note that the first axis of the PCA carried out represents about $75 \%$ of the full variance of the data both in southerly and northerly flow cases. The great variance explained by the first axis can be interpreted as all the pressure-anomaly data observed by the network used in this study being well correlated. Therefore, we can conclude that the entire pressure network is measuring a common phenomenon that simultaneously affects the valley as a whole with no significant local bias.

The surface field represented by the mean value of pressure disturbance can be described as a high/low pressure (depending on the south/north situation) centred near the mountain range and located in the middle portion. 
The surface distribution of the first PCA axis is similar to the mean values of pressure anomaly, so this axis has to be interpreted as a reinforcement/lowering of the mean anomaly, depending on the sign of the component.

The second axis (again quite similar for north/south situations) represents a gradient of pressure anomaly perpendicular to the axis of the valley, representing a displacement of the centre of the pressure disturbance on some days. In an initial assessment this component could be interpreted as a residual synoptic gradient, not evaluated by the linear interpolation used in this work. If this interpretation were correct, a correlation should be found between the relative importance of this axis every day and the value of the synoptic wind component parallel to the valley; however, no significant correlation was found between these two parameters. We conclude that this axis should be interpreted as a residual value. We should bear in mind that due to the fact that the PCA method seeks a perpendicular axis, any small variation in the numerical value of the data can force the second axis in any particular direction lacking any physical interpretation.

\section{RELATIONSHIP BETWEEN INCIDENT-AIR-MASS CHARACTERISTICS AND PRESSURE DISTURBANCE}

Following linear theory, we can deduce that pressure disturbance is caused by the dynamical effect of wind flowing against mountain; therefore, some correlation has to be found when dynamic characteristics of the incident air mass are compared with the pressure disturbance.

Related to this, Genovés and Jansá (1993) among others, have shown the excellent relationship between drag and the pressure difference between Zaragoza (to the south of the Pyrenees) and Pau (to the north) during PYREX. This pressure difference can be considered to be a crude parametrization of the pressure dipole intensity.

In order to clarify the dynamic origin of the dipole, we try to compare some characteristics of air masses incident on the Pyrenees, and pressure anomalies found within the Ebro Valley.

To characterize the pressure-anomaly field inside the Ebro Valley, we have used:

- The maximum/minimum value of the pressure disturbance observed by the measurement network.

- The maximum/minimum value of the pressure disturbance related to the first two principal axes deduced by PCA.

To characterize the dynamic aspects of incoming air masses, the following nondimensional numbers were considered:

- $\quad$ Froude number, $F r$, defined as $F r=U /\left(h_{0} N\right)$ where $U$ is the perpendicular component of the wind flowing against the mountain, $N$ the Brunt-Väisälä frequency, and $h_{0}$ a representative height of the mountain (taken to be $3000 \mathrm{~m}$ in our case). The Froude number measures the tendency of the air parcels either to go around (low Froude number) or to go over (high Froude number) the obstacles. The Froude number can be considered to be an indication of the applicability of linear theory. With high Froude numbers, the effect of the mountain on the flow is low, so linear theory can be applied. On the contrary, low Froude numbers indicate a great disturbance in the flow. The limit is a very stable air mass, with $F r$ nearly zero, moving in horizontal planes so that in these cases Drazin's theory can be applied.

- $\quad$ Rossby number, $R o$, defined as $R o=U / f a$, where $f$ is the Coriolis factor, and $a$ the representative horizontal width of the mountain (in our case $40 \mathrm{~km}$ ). The Rossby number indicates the influence of the Coriolis force on the flow: a minimal 
TABLE 2. CORRELATION COEFFICIENTS BETWEEN PRESSURE-DISTURBANCE EXTREME OR PRESSURE-DISTURBANCE EXTREME COMPONENTS ALONG THE FIRST TWO PRINCIPAL COMPONENT (PC) AXES, AND INCOMING-AIR-MASS PARAMETERS $F r$ (FROUDE NUMBER) AND $R o$ (ROSSBY NUMBER)

\begin{tabular}{cccccccc}
\hline & \multicolumn{3}{c}{ Northerly wind } & & \multicolumn{3}{c}{ Southerly wind } \\
\cline { 2 - 3 } Parameter & $\begin{array}{c}\text { Pressure } \\
\text { anomaly }\end{array}$ & PC axis 1 & PC axis 2 & & $\begin{array}{c}\text { Pressure } \\
\text { anomaly }\end{array}$ & PC axis 1 & PC axis 2 \\
\hline$F r$ & $0.38(0.40)$ & $0.91(0.00)$ & $0.51(0.24)$ & & $0.05(0.90)$ & $0.02(0.96)$ & $0.42(0.26)$ \\
$R o$ & $0.28(0.54)$ & $0.88(0.01)$ & $0.61(0.15)$ & & $0.09(0.82)$ & $0.07(0.86)$ & $0.39(0.30)$ \\
\hline
\end{tabular}

The figures in brackets are the significance levels of the non-correlation hypothesis.

effect for cases with a high Rossby number, and a significant effect with a low Rossby number.

When these parameters are calculated from radiosounding measurements we should note that any actual vertical profile represents merely a group of instantaneous atmospheric measurements. It is, therefore, necessary to follow a method in order to calculate the wind velocity and temperature vertical gradients which present a better representation of the mean characteristics of the air mass sounded. Several authors have followed different approaches to accomplish this task. In our case we have adopted the method previously used by Bénech et al. (1998) to treat PYREX data, by using the radiosoundings carried out in Toulouse, on the north side of the Pyrenees, and Zaragoza on the south (see Fig. 1), for northerly and southerly flow situations respectively. The mean wind intensity of the air mass flowing against the mountain was evaluated as the integral mean of the wind measured in the radiosounding in a layer between $400 \mathrm{~m}$ and $6000 \mathrm{~m}$. On the other hand, the mean vertical temperature gradient of the air mass was estimated from the slope of a linear regression applied to all potential temperatures measured within the same levels for a given radiosounding.

The results obtained with this approach show that in general the Brunt-Väisälä frequencies associated with the days studied in this paper are relatively homogeneous in the different soundings. From this result we can conclude that the mean wind velocity of the air mass is the determinant parameter in representing the dynamic characteristics of incident air mass; a conclusion that agrees rationally with Mass and Ferber (1990) results. We can note that the Froude numbers found are generally low ( 0.5 or less), so that intense nonlinear effects such as blocked air and the splitting effect around the mountain were expected (and later confirmed by experimental observations). Finally, we also wish to point out that calculated Rossby numbers are also low, thus the influence of the Earth's rotation on the air flow must necessarily be significant.

The correlation ratios and the significance levels of the non-correlation hypothesis (Dunn and Clark 1974) found between mean dynamic characteristics of incident air masses and the extreme pressure anomalies (maximum or minimum) observed in the Ebro Valley are shown in Table 2. This table also shows the correlation found in using the extreme pressure-anomaly values calculated from the first two principal axes obtained in our PCA.

Our conclusions from the results presented in Table 2 are as follows:

- A much better correlation is found between the Froude number and pressure anomaly when we use the component along the first axis, rather than the total anomaly, for northerly wind situations. A moderate correlation is found for the pressure anomaly along the second axis. 
- For southerly wind situations, no correlation is found for the pressure anomaly or the component along the first axis, with the Froude number. However, the results show a moderate correlation between the Froude number and the pressure-anomaly component along the second axis. In all likelihood, the complex topography at the southern edge of the Pyrenees is the cause of the low correlation generally found when southerly flows are considered. This topography probably disturbs the flow, resulting in the air-mass characteristics calculated from radiosoundings in Zaragoza becoming non-representative.

- We can note that, as expected, the correlations found with Rossby numbers follow a similar pattern to those using Froude numbers.

We can conclude that the PCA analysis is able to isolate the dynamical pressure perturbation for northerly flows as the first axis, but that this result is not true for southerly flows. Related to this, a preliminary study of a pressure perturbation calculated with a linear model and a constant vertical wind profile, seems to indicate that the first-axis component of the pressure anomaly could be directly related to the linear component of the pressure dipole.

\section{CONCLUSIONS}

The PYREX database, and especially pressure data from the microbarograph network and regular stations were used in this paper to obtain the southerly component of the pressure anomaly created by the Pyrenees. Synoptic pressure in the valley was estimated by linearly interpolating the pressure values measured by two stations remote from the study region.

The pressure anomaly, as predicted by linear theory, presents a low-pressure centre for northerly flow and a high-pressure centre for southerly flow. The maximum/minimum extremes found are of the order of $7 \mathrm{hPa}$ for both northerly and southerly flow. To make a rational classification of the pressure-anomaly patterns found in the Ebro Valley, a PCA was applied to the data. From this PCA study we found that the mean value consists of a low/high-pressure centre near the mountains, and the first axis, explaining about $75 \%$ of variance, represents a reduction or reinforcement of this centre.

The incoming air was characterized by the Froude and Rossby numbers, calculated with radiosounding data measured inside two different layers. The values indicate significant nonlinear effects and a major influence of the Earth's rotation. Good correlation was found between pressure-disturbance extremes and incident-air parameters for northerly winds, with significantly improved regression ratios for components along the first axis.

Aananasen, C. J.

Bénech, B., Koffi, E., Druilhet, A. and Durand, $\mathrm{P}$.

Bessemoulin, P., Bougeault, P., Genovés, A., Jansá, A. and Puech, D.

Blanchard, D. O. and Howard, K. W.

\section{REFERENCES}

1965 Gales in Yorkshire in February 1962. Geophys. Memo., 108, 1-44 1998 Dynamic characteristics of regional flows around the Pyrénées in view of the PYREX experiment. Part I: Analysis of the pressure and wind fields and experimental assessment of the applicability of the linear theory. J. Appl. Meteorol., 37, 3251

1993 Mountain pressure drag during PYREX. Beitr. Phys. Atmos., 66, $305-325$

1986 The Denver hailstorm of 13 June 1984. Bull. Am. Meteorol. Soc., 67, 1123-1131 
Bougeault, P., Bret, B., Lacarrére, P. 1991 and Noilhan, J.

Bougeault, P., Jansá, A., Attie, J. L., 1993 Beau, I., Benech, B.,

Benoit, R., Bessemoulin, P., Caccia, J. L., Campins, J., Carissimo, B.,

Champeaux, J. L.,

Crochet, M., Druilhet, A.,

Durand, P., Elkhalfi, A.,

Flamant, P., Genoves, A.,

Georgelin, M., Hoinka, K. P.,

Klaus, V., Koffi, E.,

Kotroni, V., Mazaudier, C.,

Pelon, J., Petitdidier, M.,

Pointin, Y., Puech, D.,

Richard, E., Satomura, T.,

Stein, J. and Tannhauser, D.

Davies, H. C. and Phillips, P. D.

Drazin, $\mathrm{P}$.

Dunn, O. J. and Clark, V. A.

Genovés, A. and Jansá, A.

Koffi, E., Bénech, B., Stein, J. and Terliuc, B.

Lyra, G.

Mass, G. F. and Ferber, G. K.

Queney, P.

Reed, R. J.

Smith, R. B.

Stein, J.

Triplet, J. P. and Roche, G.

Vazquez, L., Gordo, A. and Casals, M.
An experiment with an advanced surface parametrization in a mesobeta-scale model. Part II: The 16 June simulation. Mon. Weather Rev., 119, 2374-2392

The atmospheric momentum budget over a major mountain range: First results of the PYREX program. Ann. Geophys., 11, $395-418$

Mountain drag along the Gottard section during ALPEX J. Atmos. Sci., 42, 2093-2109

1961 On the steady flow of a fluid of variable density past an obstacle. Tellus, 13, 239-251

Applied statistics: Analysis of variance and regresssion. Wiley, New York

'Rozamiento y dipolo orográficos: resultados de las observaciones PYREX'. Technical Report, Centro meteorológico de Baleares, Instituto Nacional de Meteorología

Dynamic characteristics of regional flows around the Pyrénées in view of the PYREX experiment. Part II: Solution of a linear model compared to field measurements. J. Appl. Meteorol. 37, 53-71

Theorie der stationären leewillenströnmung in freier atmosphäre. Z. Angew. Math. Mech., 23, 1-28

Surface pressure perturbations produced by an isolated mesoscale topographic barrier. Part I: General characteristics and dynamics. Mon. Weather Rev., 118, 2579-2596

'Theory of perturbations in stratified currents with application to airflow over mountain barriers'. Misc. Rep. No 23, Department of Meteorology, University of Chicago, USA

Destructive winds caused by an orographically induced mesoscale cyclone. Bull. Am. Meteorol. Soc., 61, 1346-1355

Linear theory of stratified hydrostatic flow past an isolated mountain. Tellus, 32, 348-364

Synoptic observations and theory of orographically disturbed wind and pressure. J. Atmos. Sci., 39, 60-70

Hydrostatic flow over mountains. Adv. Geophys., 31, 1-41

Investigation of the regime diagram of hydrostatic flow over a mountain with a primitive equation model. Part I: Twodimensional flows. Mon. Weather Rev., 120, 2962-2976

1977 Météorologie Générale. École Nationale de la Météorologie

1992 'Primeros resultados sobre el Cierzo en el marco de la campaña PYREX'. III Simposio Nacional de Predicción. INM, Madrid 